\title{
The fuzzy-PID based-pitch angle controller for small-scale wind turbine
}

\author{
Quang-Vi Ngo ${ }^{1}$, Chai $\mathrm{Yi}^{2}$, Trong-Thang Nguyen ${ }^{3}$ \\ ${ }^{1}$ Faculty of Electronic and Electrical Engineering, Haiphong Private University, Vietnam \\ ${ }^{1,2}$ College of Automation, Chongqing University, China \\ ${ }^{3}$ Faculty of Electrical and Electronic Engineering, Thuyloi University, Vietnam
}

\begin{tabular}{|c|c|}
\hline Article Info & ABSTRACT \\
\hline Article history: & \multirow{6}{*}{$\begin{array}{l}\text { This paper aims to design the pitch angle control based on proportional- } \\
\text { integral-derivative (PID) controller combined with fuzzy logic for small- } \\
\text { scale wind turbine systems. In this system, the angle of pitch is controlled by } \\
\text { the PID-controller with their parameter is tuned by the fuzzy logic controller. } \\
\text { This control system can compensate for the nonlinear properties of the wind } \\
\text { speed and pitch angle. A comparison between the fuzzy-PID-controller with } \\
\text { the conventional PID-controller is carried out. The effectiveness of the } \\
\text { method is determined by the simulation results of a small wind turbine using } \\
\text { a permanent magnet generator (PMSG). }\end{array}$} \\
\hline Received Jun 17, 2019 & \\
\hline Revised Sep 11, 2019 & \\
\hline Accepted Nov 14, 2019 & \\
\hline Keywords: & \\
\hline Fuzzy Logic & \\
\hline
\end{tabular}

PID

Pitch

Small-Scale

Wind turbine

This is an open access article under the CC BY-SA license.

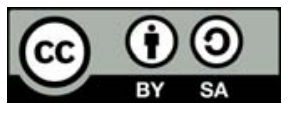

Corresponding Author:

Trong-Thang Nguyen,

Faculty of Electrical and Electronic Engineering,

Thuyloi University,

175 Tay Son, Dong Da, Hanoi, Vietnam.

Email: nguyentrongthang@tlu.edu.vn

\section{INTRODUCTION}

The wind energy is increasingly being studied by scientists around the world [1-3]. Especially, a Small-Scale Wind Turbine (SSWT) is an important research topic because of the SSWT is a renewable, clean, sustainable power source. Electricity production from SSWT is installed in some far places such as islands with the decentralized grid systems $[4,5]$. The exploitation of wind power based on pitch angle control is proposed through research [6-8]. This control method can eliminate the elements such as a dump load [9], a passive pitch controller [10] and a furling system [11], so it reduces the system cost and the cumbersome while controlling.

Pitch angle control of SSWT is similar to large-scale wind turbine systems. The target of the control system depends on the two operating regions of the wind speed. The low-speed region is that the speed of wind is lower than the norm value. In this region, the speed of turbine is adjusted in order that the extracted energy from the turbine reaches a maximum. The high-speed region is that the speed of wind exceeds the norm value. In this region, the output power of a generator must be limited by norm value through controlling the angle of inclination due to the generator power and converter being limited in output power.

The conventional control method of pitch angle has been proposed in research $[12,13]$, it used the PI and PID controller. These controllers are widely used, but its disadvantage is that if the operating point is changed, the system performance is deteriorated. These controllers have also been improved by nonlinear PI 
and PID controllers in the research $[14,15]$, but it needs to find the accurate mathematical models for windturbines, so it is difficult to implement in practice.

The predictive control model has been given in research [16], the future control signals are calculated based on the past and present signals to produce the appropriate pitch angle signals with reality. But this method has the disadvantage that the system will be unstable if there is a large deviation in output power. Another method used for controlling the pitch angle is a sliding control method, which is given in the paper [17]. This is a high speed method of pitch angle control system. However, the disadvantage of this method is that the efficiency depends on the accuracy of the mathematical model and there is the chattering.

The adaptive controller has been given in research [18], the gain scheduling controller is used to adjust the PID parameters. This controller is built in order that the system works optimally in a certain sampling period, but the wind turbine model is nonlinear, so the times for determining the parameters of the controller are long.

Fuzzy logic control (FLC) was proposed to control the large-scale wind turbine systems [19-21], with the input parameters of the controller are generator power and wind speed. FLC method is reliable, sustainable with nonlinear characteristics of the pitch angle of wind turbines. However, this system needs a speed-sensor [22, 23], so the system cost increases.

There is very little research on controlling the pitch angle of the SSWT. These research only solve the limit of wind power capacity by methods such as a dump load, a passive controller and a furling system [9-11]. Therefore, in this research, the authors will design the PID controller with fuzzy self-tuning for adjusting the pitch angle applied for SSWT. This control method is a combination of traditional PID controller with fuzzy logic. This method has the advantages of the PID controller, which are the fast response and the simple structure. It also has the advantages of the fuzzy controller because that the author's experience is included in the system. The results obtained by PID controller with the Fuzzy self-tuning are compared to the traditional PID controller. The results prove that the PID controller with the Fuzzy selftuning has better properties.

\section{THE WIND TURBINE SYSTEMS}

\subsection{The classification of turbine}

The paper [5] showed that wind turbines with these diameters of $3 \mathrm{~m}$ to $10 \mathrm{~m}$ and powers of $1.4 \mathrm{~kW}$ $20 \mathrm{~kW}$ are called SSWT. The classification of the rotor diameter and the power range of the horizontal axis wind turbine are shown in Table 1. The research object of this paper is the Household type.

Table 1. The classification of horizontal axis wind turbine [5]

\begin{tabular}{|c|c|c|c|c|c|c|c|}
\hline \multicolumn{2}{|l|}{ Type } & \multicolumn{2}{|c|}{ Standard power rate $(\mathrm{kW})$} & \multicolumn{2}{|c|}{ Swept area $\left(\mathrm{m}^{2}\right)$} & \multicolumn{2}{|c|}{ Rotor diameter $(\mathrm{m})$} \\
\hline & Micro & 0.004 & 0.25 & 0.2 & 1.2 & 0.5 & 1.25 \\
\hline \multirow[t]{2}{*}{ Small sacle } & Mini & 0.25 & 1.4 & 1.2 & 7.1 & 1.25 & 3 \\
\hline & Household & 1.4 & 16 & 7 & 79 & 3 & 10 \\
\hline \multicolumn{2}{|c|}{ Small commercial } & 25 & 100 & 79 & 314 & 10 & 20 \\
\hline \multicolumn{2}{|c|}{ Medium commercial } & 100 & 1000 & 314 & 1963 & 20 & 50 \\
\hline \multicolumn{2}{|c|}{ Large commercical } & 1000 & 3000 & 1963 & 7854 & 50 & 100 \\
\hline
\end{tabular}

\subsection{The model of the wind turbine}

The turbine torque is calculated as follows [8]:

$$
T_{w}=\frac{1}{2} \pi \rho R^{3} \frac{C_{P}(\lambda, \beta)}{\lambda} v_{w}^{2}
$$

where: $v_{\omega}$ is the wind speed $(\mathrm{m} / \mathrm{s}) ; \mathrm{R}$ is the blade radius $(\mathrm{m}) ; \rho$ is the air density $\left(\mathrm{kg} / \mathrm{m}^{3}\right) ; \lambda$ is the tip-speed ratio; $\beta$ is the pitch angle.

$C_{P}$ is the coefficient of energy conversion which is determined by the following equation [24]:

$C_{P}(\lambda, \beta)=c_{1}\left(\frac{c_{2}}{\lambda_{i}}-c_{3} \beta-c_{4}\right) e^{\frac{-c_{5}}{\lambda_{i}}}+c_{6} \lambda$

Where:

$\frac{1}{\lambda_{i}}=\frac{1}{\lambda+0.08 \beta}-\frac{0.035}{1+\beta^{3}}$

$c_{1}=0.5176, c_{2}=116, c_{3}=0.4, c_{4}=5, c_{5}=21$ and $c_{6}=0.0068$

Int J Pow Elec \& Dri Syst Vol. 11, No. 1, Mar 2020 : $135-142$ 


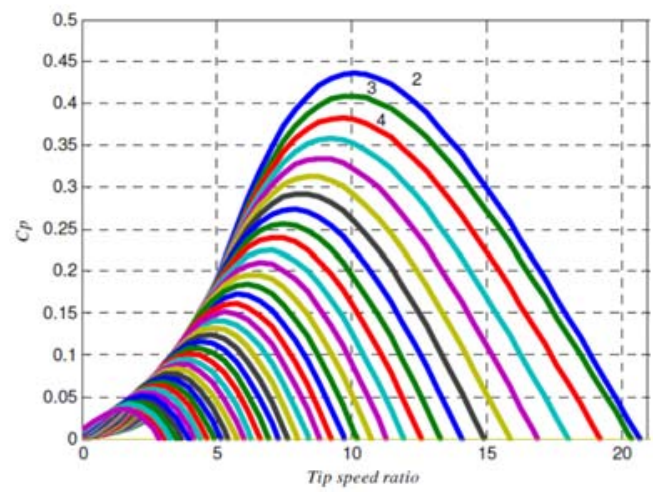

Figure 1. The power coefficient $C_{P}(\lambda, \beta)$

\subsection{The characteristics of wind turbines}

During operation, it is necessary to regularly adjust the turbine speed according to the wind speed and the energy into the turbine blade. The system works in order for receiving the maximum energy at high wind speeds and at low wind speeds, and to ensure safety for turbine systems [21]. The characteristics of power depended the wind speed of the adjustment process are shown as Figure 2.

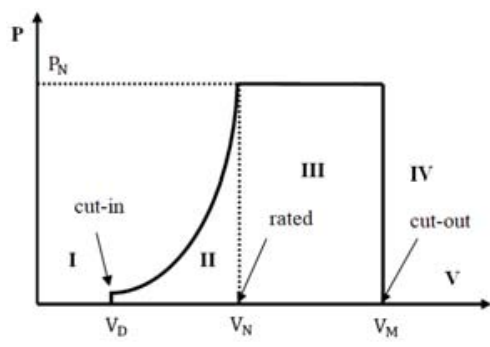

(a) The wind turbine's power control regions $[6,21,23]$

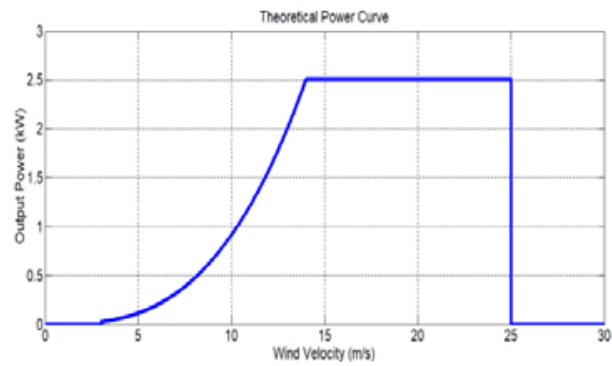

(b) The wind turbine's power control regions in the case of the power of $2.5 \mathrm{~kW}$

Figure 2. The dependence on the wind speed of wind turbine power

The operation of a turbine in Figure 2 has 4 main regions:

- The first region is that the speed of wind is smaller than the cut-out value $\left(V_{D}\right)$. In this region, wind turbines interrupt and do not generate electricity.

- The second region is the wind speed in the range $\left(V_{D}, V_{N}\right)$. This is the optimal region of energy transformation where the wind speed is needed to control in order the system get the maximum power.

- The third region has increased wind power, but the turbine's power is limited by the rated power $\left(\mathrm{P}_{\mathrm{N}}\right)$. In this region, the control system of pitch angle will operate.

- In the fourth region, the speed of wind is larger than the maximum value so the turbine can withstand. The turbine will be stopped by the mechanical braking system to protect the system.

\subsection{Identifying the control object}

The object must be controlled that is the hydraulic system or electromechanical devices [8]. We chose the motor servo for the pitch actuator for easy-to-adjust the characteristics as well as a simple mathematical model of simulation. The pitch servo unit is modeled as an Integrator or a first-order delay system, with the time constant T_servo is in the range of $0.2-0.3(\mathrm{~s})$ and $\beta$ is in the range of -2 to 30 degrees [24]. The differential equation of the servo motor is as follows [20]:

$$
\frac{d \beta}{d t}=-\frac{1}{T_{\text {servo }}} \beta+\frac{1}{T_{\text {servo }}} \beta_{\text {ref }}
$$


The transfer function of a servo motor is as follows:

$$
\frac{\beta(s)}{\beta_{\text {ref }}(s)}=\frac{1}{T_{\text {servo }} s+1}
$$

Where: $\quad \beta_{\min } \leq \beta \leq \beta_{\max }$

$\dot{\beta}(t)_{\min } \leq \dot{\beta}(t) \leq \dot{\beta}(t)_{\max }$

$\beta_{\max }$ is the maximum of pitch angle; $\beta_{\min }$ is the minimum and of pitch angle.

\section{THE CONTROLLERS USED FOR THE SSWT}

Today, because of the achievements of control science and technology, there are many types of conventional and modern controllers, which have met the requirement of control efficiency such as fuzzy, neuron, adaptive, optimization, predictive and sliding controllers. Specially, PID and FLC are applied much to SSWT because it features simple structure and does not need to know the exact mathematical model of the object. These controllers have the following structure.

\subsection{Conventional PID controller}

The PID controller adjusts the generator's rotor speed or the generator's output power by changing the angle of pitch. The speed error of generator or generator power will be the input of the PID controller. The PID output signal ( $\beta$ _ref) is expressed as follows equation [21]:

$$
\beta_{\text {ref }}(t)=K_{P} e(t)+K_{I} \int e(t) d t+K_{D} \frac{d e(t)}{d t}
$$

Where: $K_{P}, K_{I}$ and $K_{D}$ are the parameter of the PID controller.

The error is:

$$
e(t)=-\omega_{r}^{r e f}(t)+\omega_{r}(t)
$$

Where: $e$ is the error of generator speed, $\omega_{r}^{r e f}$ denotes the reference speed, $\omega_{r}$ denotes the generator speed. The control system is shown in below figure.

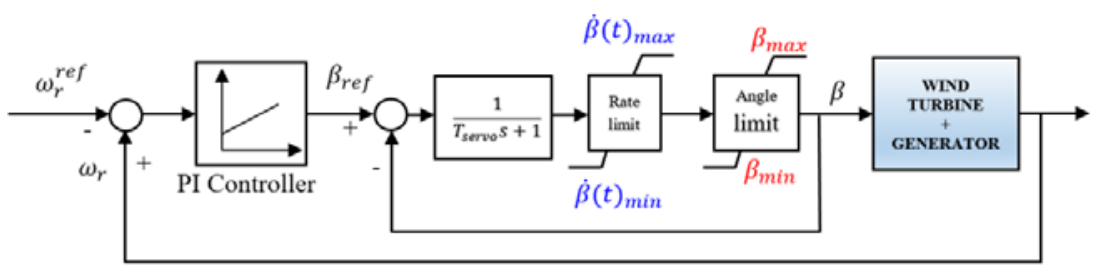

Figure 3. The pitch angle control scheme using the PID controller

\subsection{Fuzzy logic controller (FLC)}

The control scheme used fuzzy logic is shown as Figure 4. The the generator's output power or the wind speed is the input signal of the FLC $[23,25]$.

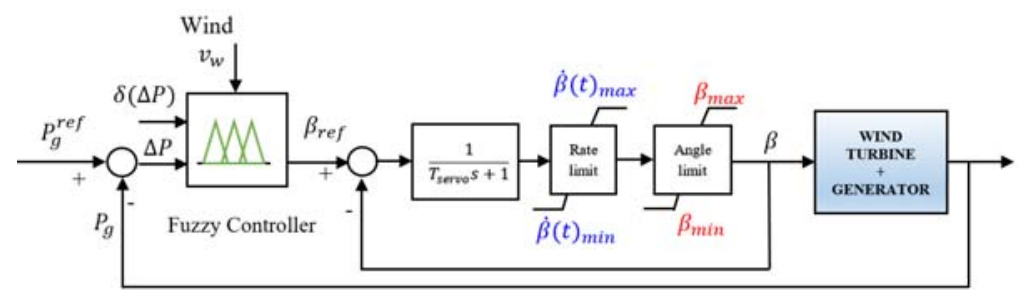

Figure 4. The pitch angle control scheme using the FLC 


\section{DESIGNING THE FUZZY-PID CONTROLLER FOR THE SSWT}

The set of FLC rules is designed based on the human experience. It also does not need the exact object mathematical model. In this research, the authors design the Fuzzy-PID controller for a small wind turbine system. This system is shown in Figure 5. The fuzzification of the input and output variables are shown in Figure 6. Input and output variables have triangular forms for higher sensitivity, especially when the variables reach zero. The width of the variable is adjusted according to the parameters of system.

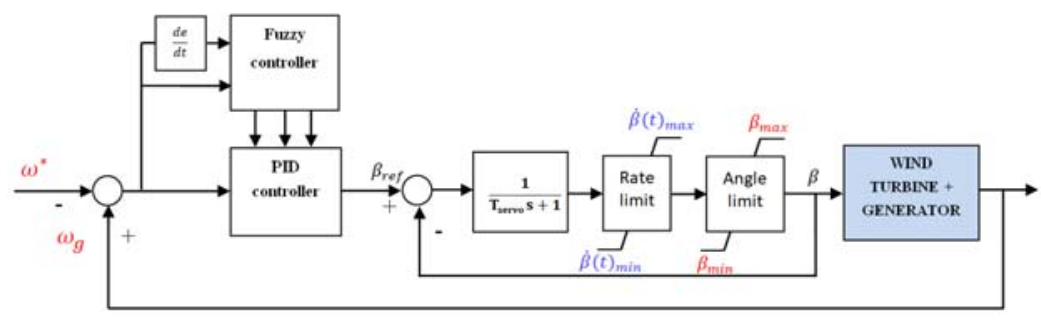

Figure 5. The pitch angle control system with the fuzzy-PID controller

Designing a fuzzy controller has the following steps:

- Fuzzification: Converting the input variable from the real value to the fuzzy value.

- Setting the fuzzy logic rules "if ...then"

- Defuzzification: Converting output value from the fuzzy value to the real value for controlling the object.

The Fuzzy-PID the controller operates based on the error between of generator speed $\left(\omega_{g}\right)$ and MPPT speed $\left(\omega^{*}\right)$ :

$$
\Delta \omega=\omega_{g}-\omega^{*}
$$

The input value has five linguistic levels with the following names: negative low (NL), negative small (NS), zero (ZE), positive small (PS) and positive large (PL). The output value also has five linguistic levels with the following names: positive small (PS), positive medium (PM), positive medium-large (PML), positive large (PL), positive large (PL) and positive very-large (PVL). The authors propose 75 control rules for FLC which are shown in Table 3, Table 4, and Table 5. These control rules are defined by expert knowledge and experience of the authors.

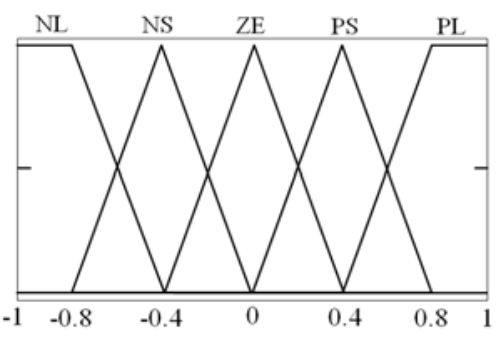

(a) The input linguistic levels $(e$ and $\dot{e})$

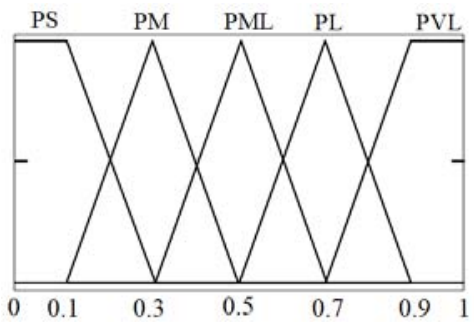

(b) The linguistic levels of output signal $\left(K_{P}, K_{I}, K_{D}\right)$

Figure 6. The fuzzy logic controller's membership functions

Table 2. The system responding when changing the parameters [26, 27]

\begin{tabular}{llll}
\hline & Steady state error & Settling time & Overshoot \\
\hline Increasing Kp & Decrease & Small Increase & Increase \\
Increasing Ki & Large Decrease & Large & Increase \\
Increasing Kd & Minor Change & Decrease & Decrease \\
\hline
\end{tabular}


Table 3. The rule base for $K_{p}$ tuner

\begin{tabular}{lllllll}
\hline \multirow{2}{*}{$K p$} & & & \multicolumn{5}{c}{$\dot{e}$} \\
& & $N L$ & $N S$ & $Z E$ & $P S$ & $P L$ \\
\hline \multirow{4}{*}{$e$} & $N L$ & $P S$ & $P S$ & $P S$ & $P M L$ & $P M L$ \\
& $N S$ & $P S$ & $P M$ & $P M$ & $P L$ & $P M L$ \\
& $Z E$ & $P S$ & $P M$ & $P M L$ & $P L$ & $P L$ \\
& $P S$ & $P M$ & $P M$ & $P L$ & $P L$ & $P L$ \\
& $P L$ & $P M L$ & $P M L$ & $P L$ & $P V L$ & $P V L$ \\
\hline
\end{tabular}

Table 4. The rule base for $K_{i}$ tuner

\begin{tabular}{lllllll}
\hline \multirow{2}{*}{$K i$} & & & \multicolumn{4}{c}{$\dot{e}$} \\
& & $N L$ & $N S$ & $Z E$ & $P S$ & $P L$ \\
\hline \multirow{4}{*}{$e$} & $N L$ & $P V L$ & $P V L$ & $P L$ & $P L$ & $P M L$ \\
& $N S$ & $P V L$ & $P L$ & $P L$ & $P M L$ & $P M$ \\
& $Z E$ & $P V L$ & $P M L$ & $P M L$ & $P L$ & $P S$ \\
& $P S$ & $P M$ & $P M L$ & $P S$ & $P L$ & $P S$ \\
& $P L$ & $P S$ & $P M L$ & $P S$ & $P V L$ & $P S$ \\
\hline
\end{tabular}

Table 5. The rule base for $K_{d}$ tuner

\begin{tabular}{cllllll}
\hline \multirow{2}{*}{$K d$} & & & \multicolumn{4}{c}{$\dot{e}$} \\
& & $N L$ & $N S$ & $Z E$ & $P S$ & $P L$ \\
\hline \multirow{4}{*}{$e$} & $N L$ & $P S$ & $P S$ & $P M$ & $P M$ & $P M L$ \\
& $N S$ & $P S$ & $P M$ & $P M$ & $P M L$ & $P M L$ \\
& $Z E$ & $P S$ & $P M$ & $P M L$ & $P L$ & $P V L$ \\
& $P S$ & $P M$ & $P M L$ & $P L$ & $P L$ & $P V L$ \\
& $P L$ & $P M L$ & $P V L$ & $P L$ & $P V L$ & $P V L$ \\
\hline
\end{tabular}

Parameters of the wind turbine system and PMSG generator are shown in Table 6 and Table 7.

Table 6. The small wind turbine's parameters

\begin{tabular}{ccccccc}
\hline Rated wind speed & Cut-out speed & Cut-in speed & Max.power conv. Coefficient & Air density & Blade radius & Rated power \\
\hline $14(\mathrm{~m} / \mathrm{s})$ & $25(\mathrm{~m} / \mathrm{s})$ & $3(\mathrm{~m} / \mathrm{s})$ & 0.47 & $1.225\left(\mathrm{~kg} / \mathrm{m}^{3}\right)$ & $1.65(\mathrm{~m})$ & $2.5(\mathrm{~kW})$ \\
\hline
\end{tabular}

Table 7. The parameters of PMSG

\begin{tabular}{cccccc}
\hline Rated power & Number of pole-pares & Rotor speed $(\omega)$ & Stator resistance $\left(\mathrm{R}_{\mathrm{s}}\right)$ & $\begin{array}{c}\text { Stator inductance }\left(\mathrm{L}_{\mathrm{s}}\right) \\
\text { Permanent magnetic } \\
\text { flux }\end{array}$ & \\
\hline $2.5(\mathrm{~kW})$ & 8 & $104(\mathrm{rad} / \mathrm{s})$ & $0.36(\Omega)$ & $1.2(\mathrm{mH})$ & $0.25(\mathrm{~Wb})$ \\
\hline
\end{tabular}

\section{THE RESULTS}

Figure 7 the wind speed from $10 \mathrm{~m} / \mathrm{s}$ to $16 \mathrm{~m} / \mathrm{s}$. Figure 8 shows the speed of the generator, the quality of the Fuzzy-PID controller is compared with the traditional PID controller. In which, the red line is generator speed in the case of Fuzzy-PID controller. The blue broken line is generator speed in the case of the raditiona PID controller. The results show that the Fuzzy PID controller has a less oscillation than the PID controller.

Figure 9 shows the PMSG's output power. The power characteristic at the time $t=2 \mathrm{~s}$ shows that the speed of the wind source is $10 \mathrm{~m} / \mathrm{s}$, the output power is still stable. In the case of low wind power, the FuzzyPID controller gives better quality.

Figure 10 shows the turbine's pitch angle. The result shows that when the wind power changes, the ability to set and stabilize the value of Fuzzy-PID controller is also better.

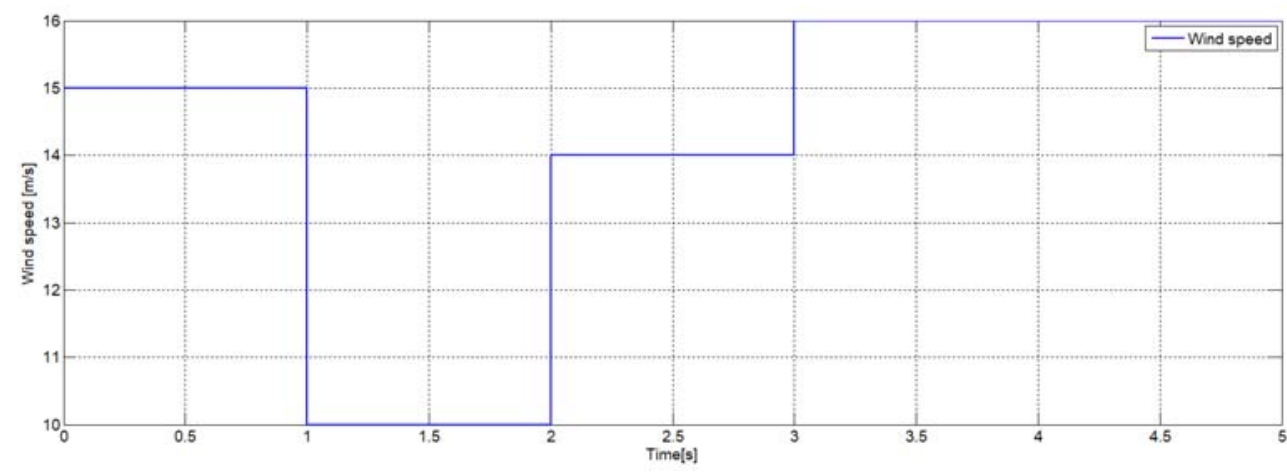

Figure 7. The wind source profile with wind speed is valid from $10 \mathrm{~m} / \mathrm{s}-16 \mathrm{~m} / \mathrm{s}$

Int J Pow Elec \& Dri Syst Vol. 11, No. 1, Mar 2020 : 135 - 142 


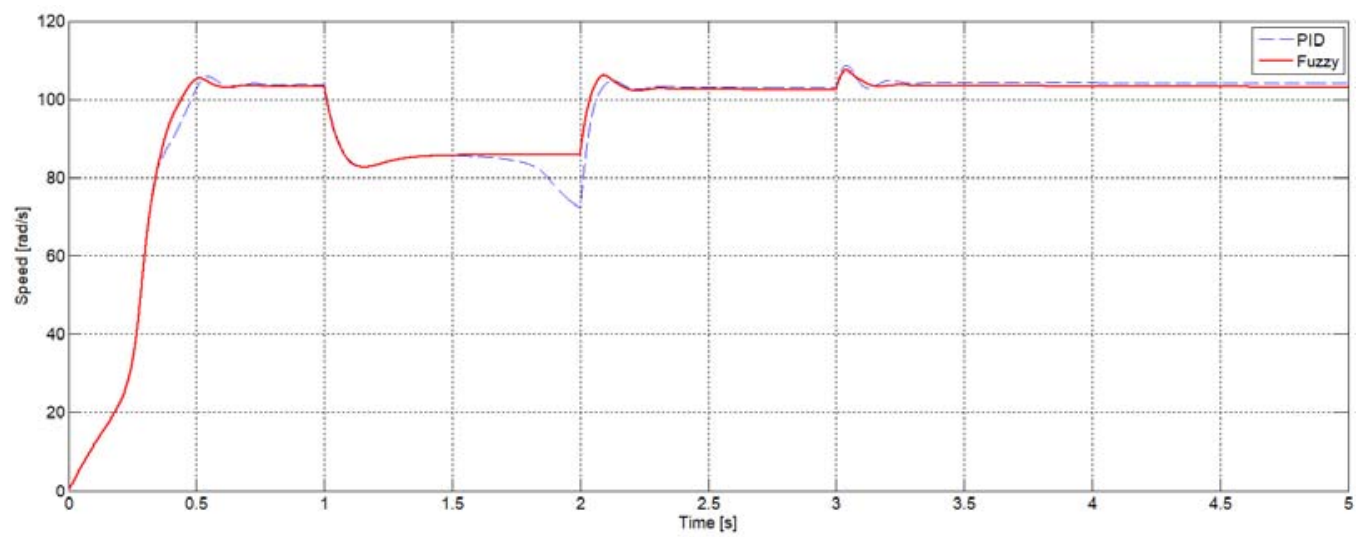

Figure 8. The generator speed of PMSG

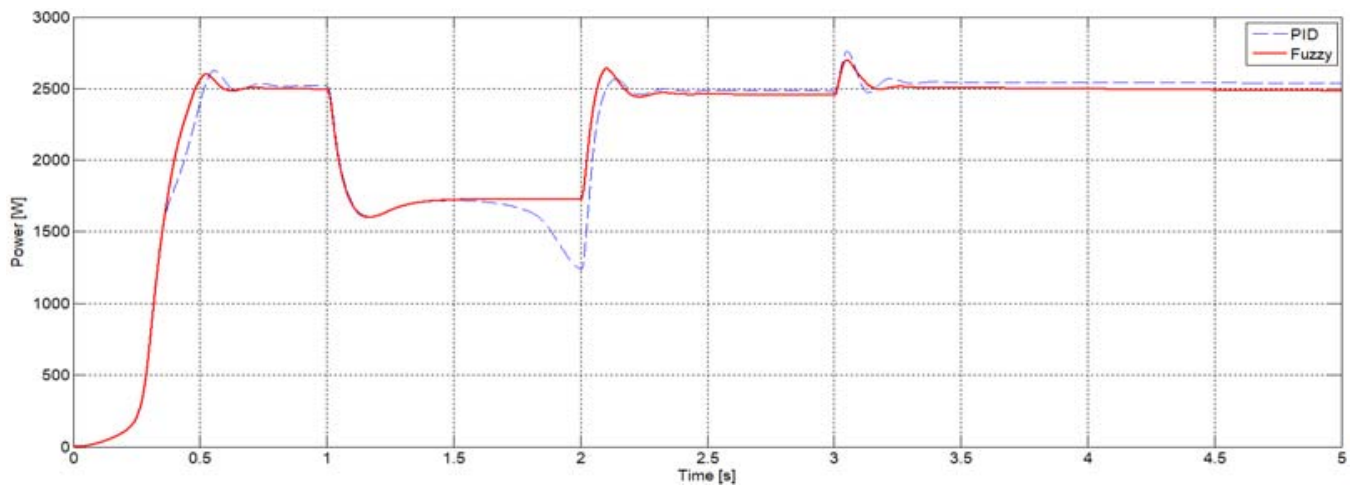

Figure 9. The output power of PMSG

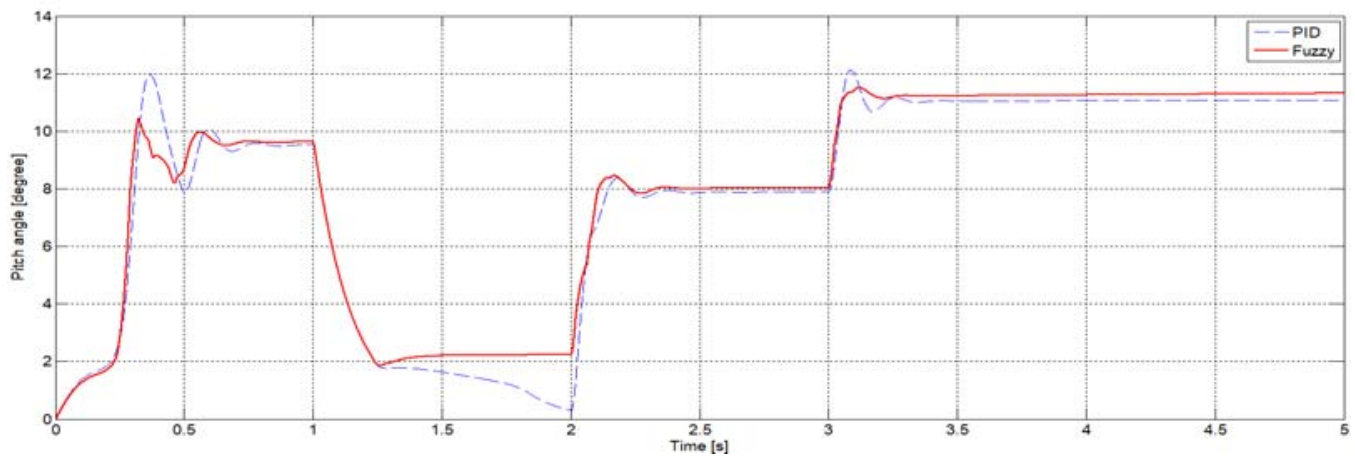

Figure 10. The wind turbin's pitch angle

\section{CONCLUSION}

The pitch angle control is the most popular method for controlling the aerodynamic energy generated by wind turbines's blades. The authors have successfully proposed the Fuzzy-PID-based controller for controlling the SSWT's pitch angle. This system has removed the auxiliary systems such as the dump load, the passive pitch and the furling. In the research, the quality of the Fuzzy-PID controller is compared with the traditional PID controller. The results show that the system with the Fuzzy-PID controller has a better quality. Therefore, this proposal is necessary and practical. 


\section{REFERENCES}

[1] Bouderbala, Manale, et al., "Direct and indirect vector control of a doubly fed induction generator based in a wind energy conversion system," International Journal of Electrical and Computer Engineering (IJECE), vol. 9, No 3, pp. 1531-1540, 2019.

[2] Sakthi, S. S., Santhi, R. K., Krishnan, N. M., Ganesan, S., and Subramanian, S., "wind integrated thermal unit commitment solution using grey wolf optimizer," International Journal of Electrical and Computer Engineering (IJECE), vol. 7, no. 5, pp. 2309-2320, 2017.

[3] Rabyi, Kaoutar; Mahmoudi, Hassane, "Energy storage of DFIG based wind farm using D-STATCOM," International Journal of Electrical and Computer Engineering (IJECE), vol. 9, No. 2, pp. 761-770, 2019.

[4] R. H. Eckstein, T. B. Lazzarin and I. Barbi, "Proposed power and control system for small scale wind turbines connected to the grid," 3rd Renewable Power Generation Conference (RPG 2014), Naples, pp. 1-6, 2014.

[5] Tummala A., Velamati R. K., Sinha D. K., et al., "A review on small scale wind turbines," Renewable and Sustainable Energy Reviews, vol. 56, pp.1351-1371, 2016.

[6] Rocha P. A. C., Carneiro d A. J. W., Lima R. J. P., et al., "The effects of blade Pitch angle on the performance of small-scale wind turbine in urban environments," Energy, vol. 148, pp. 169-178, 2018.

[7] Nagai B. M., Ameku K., Roy J. N., "Performance of a $3 \mathrm{~kW}$ wind turbine generator with variable Pitch control system," Applied Energy, vol. 86, no. 9, pp. 1774-1782, 2009.

[8] F. Scherillo, L. Izzo, D. P. Coiro and D. Lauria, "Fuzzy logic control for a small Pitch controlled wind turbine," International Symposium on Power Electronics Power Electronics, Electrical Drives, Automation and Motion, Sorrento, pp. 588-593, 2012.

[9] Hee-Sang Ko, Gi-Gap Yoon, Won-Pyo Hong and Juri Jatskevich, "Control of hybrid wind power generation system with dump load using advanced fuzzy-robust controller," International Conference on Electrical Machines and Systems (ICEMS), Seoul, pp. 219-226, 2007.

[10] Chen Y. J., Tsai Y. F., Huang C. C., et al., "The design and analysis of passive pitch control for horizontal axis wind turbine," Energy Procedia, vol. 61, pp. 683-686, 2014.

[11] Audierne E., Elizondo J., Bergami L., et al., "Analysis of the furling behavior of small wind turbines," Applied Energy, vol. 87, no. 7, pp. 2278-2292, 2010.

[12] Anwar M. N., Pan S., Ghosh S., "PI controller design for Pitch control of large wind turbine generator," International Conference on Energy. IEEE, pp.1-6, 2016.

[13] Hwas A., and Katebi R., "Wind turbine control using PI pitch angle controller," ifac proceedings volumes, vol. 45, No. 3, pp. 241-246, 2012.

[14] Liu, X., Yu, W., Yang, L., and Ma, Q., "Research on variable-pitch control strategy of wind turbine based on the nonlinear PID," In 2017 Chinese Automation Congress (CAC), pp. 299-303, 2017.

[15] Ren Y., Li L., Brindley J., et al., "Nonlinear PID control for variable Pitch wind turbine," Control Engineering Practice, vol 50, pp. 84-94, 2016.

[16] Pahasa J., Ngamroo I., "Model predictive control-based wind turbine blade Pitch angle control for alleviation of frequency fluctuation in a smart grid," Electrical Engineering Congress. IEEE, pp. 1-4, 2014.

[17] Lee S. H., Joo Y. J., Back J., et al., "Sliding mode controller for torque and Pitch control of wind power system based on PMSG," International Conference on Control Automation \& Systems. IEEE, pp. 1079-1084, 2010.

[18] Luo Q., Yang Q., Han C., et al., "Pitch angle controller of variable-speed wind turbine based on L1 adaptive control theory," IEEE 2014 International Conference on Mechatronics and Control (ICMC) - Jinzhou, China, pp. 955-960, 2014.

[19] A. V. de Almeida Macêdo and W. S. Mota, "Real time simulations of wind turbine with Pitch angle control using Fuzzy Logic," 11th IEEE/IAS International Conference on Industry Applications, Juiz de Fora, pp. 1-7, 2014.

[20] A. Abir, D. Mehdi and S. Lassaad, "Pitch angle control of the variable speed wind turbine," 17th International Conference on Sciences and Techniques of Automatic Control and Computer Engineering (STA), Sousse, pp. 582-587, 2016.

[21] A. S. Al-Toma, G. A. Taylor and M. Abbod, "Intelligent Pitch angle control scheme for variable speed wind generator systems," 52nd International Universities Power Engineering Conference (UPEC), Heraklion, pp. 1-6, 2017.

[22] D. C. Vega, J. A. Marin and R. T. Sánchez, "Pitch angle controllers design for a horizontal axis wind turbine," IEEE International Autumn Meeting on Power, Electronics and Computing (ROPEC), Ixtapa, pp. 1-6, 2015.

[23] Jianzhong Zhang, Ming Cheng, Zhe Chen and Xiaofan Fu, "Pitch angle control for variable speed wind turbines," Third International Conference on Electric Utility Deregulation and Restructuring and Power Technologies, Nanjing, pp. 2691-2696, 2008.

[24] T. L. Van, T. H. Nguyen and D. Lee, "Advanced Pitch angle control based on fuzzy logic for variable-speed wind turbine systems," IEEE Transactions on Energy Conversion, vol. 30, no. 2, pp. 578-587.

[25] Naik, K. A., and Gupta, C. P., "Fuzzy logic based pitch angle controller/or SCIG based wind energy system," In Recent Developments in Control, Automation \& Power Engineering (RDCAPE), IEEE, pp. 60-65, 2017.

[26] Trong T. N., Tien B. N., Thanh H. N., et al., "The controller of DFIG power fed into the grid basing on the rotor similar signal method," Applied Mechanics and Materials, vol. 415, pp. 245-249, 2013.

[27] Vaishnav, S. R., and Khan, Z. J., "Performance of tuned PID controller and a new hybrid fuzzy PD+ I controller," World Journal of Modelling and Simulation, vol. 6, no. 2, pp. 141-149, 2010. 